\title{
Studies on Genetic Parameters for Quality Traits and Yield Components in Basmati Rice (Oryza sativa L.)
}

\author{
Amod Kumar ${ }^{1}$, Shiv Kumar ${ }^{1}$, Sarvendra Singh ${ }^{2}$, Janeshwar Prasad ${ }^{1}$, \\ A. S. Jeena ${ }^{3 *}$ and M. C. Upreti ${ }^{3}$ \\ ${ }^{1}$ Department of Agricultural Botany, ${ }^{2}$ Department of Agricultural Entomology, \\ R.M.P. (P.G.) College, Gurukul Narsan (Haridwar)-247670 Uttarakhand, India \\ ${ }^{3}$ Department of Genetics and Plant Breeding, G B Pant University of Agriculture and \\ Technology, Pantnagar-263145 (Uttarakhand), India \\ *Corresponding author
}

\section{A B S T R A C T}

\begin{tabular}{|l|}
\hline Ke y w or d s \\
Paddy, Oryza sativa \\
L., Variability, \\
yield, quality \\
\hline Article Info \\
\hline $\begin{array}{l}\text { Accepted: } \\
18 \text { May } 2020 \\
\text { Available Online: } \\
\text { 10 June } 2020\end{array}$ \\
\hline
\end{tabular}

Thirty basmati rice genotypes were evaluated in RBD with three replications with an objective of assessing the genetic variability, heritability, genetic advance for twenty-two yield and quality characters. The results of ANOVA revealed that the mean sum of squares among the genotypes for all the characters were highly significant indicating the presence of ample amount of variability which can be exploited for selection of characters for crop improvement programme. The value of PCV and GCV was observed highest in case of grain weight per plant followed by water absorb by $10 \mathrm{~g}$ kernel and number of grains per panicle. Heritability in broad sense was found high for all characters, while genetic advance as a percent of mean was recorded high for all characters except hulling \%, for which moderate GAM was observed. On the basis of study, preponderance of additive gene action was revealed for all the traits except hulling \%. The most promising donors identified for grain yield were SKG-2017-56, SKG-2017-75, SKG-2017-65, SKG-201759, SKG-2017-66. These genotypes can be used for further breeding programme to improve the yield potential of the varieties.

\section{Introduction}

Rice occupies about $23.3 \%$ of gross cropped area and contributes $43 \%$ of total food grain production and $46 \%$ of the total cereal production of the country. India ranks second in production next to China among the rice growing countries in the world. The systematic breeding programme involves the steps like creating genetic variability practicing selection and utilization of selected genotypes to evolve promising varieties. The development of high yielding rice cultivars is the main objective of any rice breeding programmes in the world.

Identification of better genotypes with desirable traits and their subsequent use in breeding programme could be helpful for successful varietal development. 
Yield is quantitative character and is governed by many genes having smaller effects i.e., polygenes. It is also influenced by differential contribution of different morphological characters. Thus, we can say that the yield is the final product of yield components. These components may affect the yield directly or indirectly. The nature and extent of genetic variation governing the inheritance of characters and association will facilitate effective genetic improvement.

Information on the extent of genetic variability as well as heritability among the agronomically important traits is the requirement to design a suitable plant breeding method. It's very important for a plant breeder to have knowledge of genetic variability and the amount of heritable variation for important traits. Sometimes the trait of interest is influenced by the environmental conditions prevailing, especially in case of polygenic characters so it becomes important to partition the total variability components, to have information regarding the nature and extent of actual variability present.

Improvement in crop depend upon the magnitude of genetic variability in economic characters therefore, the evaluation and utilization of genetic variability in desired direction becomes extremely important in any crop improvement programme.

In this regard, it is necessary to survey the available useful variability and nature of association among the various plant characters in the basic material. Earlier workers also emphasized the significance of components approach in formulating a successful breeding programme. Heritability on the other hand is a parameter widely used in establishment of breeding programs and formation of selection indices (Falconer, 1985)as it gives an idea about the transmissibility of the trait of interest. As it is difficult to select suitable parents for poly genetically controlled characters, therefore, for efficient selection of superior parents there's a need of adequate genetic variation as well as considerable heritability of the trait of interest.

Broad sense heritability is defined as the ratio of genotypic variance to phenotypic variance and expressed in percentage. Heritability along with genetic advance helps in assessing the amount of improvement that can be achieved through selection and gives an idea about which type of crop improvement methodology would work. Genetic advance in simple words is the expected response to selection and is denoted as GA.

It gives an implication of effectiveness of selection under a particular condition for trait of interest. Enlighted by these facts, the present research work was taken up to assess the extent of genetic and phenotypic variability, heritability and genetic advance for yield and its components in rice.

\section{Materials and Methods}

The present study was conducted with 30 improved genotype of basmati rice at Research farm of R.M.P. P.G. College, Gurukul Narsan, Haridwar (Uttarakhand). The Gurukul Narsan is situated in the foothills of Shivalik range of Himalaya and falls in the humid sub-tropical climate Zone.

The Material was planted in a randomized complete block design with three replications in the plot size of $2 \mathrm{~m}^{2}$ keeping $20 \times 15 \mathrm{~cm}$ spacing. The observations were recorded on a random sample of 10 plants from each plot for 22 quantitative characters viz., Days to $50 \%$ flowering, days to maturity, plant height (cm), number of tillers per plant, panicle length $(\mathrm{cm})$, flag leaf length $(\mathrm{cm})$, flag leaf 
with $(\mathrm{cm})$, number of grains per panicle, grain weight per panicle $(\mathrm{g}), 100$ grain weight $(\mathrm{g})$, 100 kernel weight (g), hulling (\%), kernel length before cooking $(\mathrm{mm})$, kernel breadth before cooking $(\mathrm{mm})$, kernel length after cooking $(\mathrm{mm})$, kernel breadth after cooking $(\mathrm{mm})$, L:B ratio, kernel elongation ratio, breath increase ratio after cooking, 100 kernel weight after cooking $(\mathrm{g})$, water absorb by 10 gm kernel (ml), grain weight per plant (g).

Genetic parameters viz., Mean, Range, Coefficients of variability (PCV and GCV) along with heritability in broad sense, genetic advance and genetic advance as percent of mean were estimated for the character studied. Analysis of variance, which was carried out as per methodology advocated by Panse and Sukhatme (1967), permits estimation of phenotypic, genotypic and environmental coefficients of variability.

PCV and GCV were calculated using the formula given by Burton (1952), heritability in broad sense $\left(\mathrm{h}^{2}\right)$ by Burton and De Vane (1953) and genetic advance i.e. the expected genetic gain was calculated by using the procedure given by Johnson et al., (1955). GCV and PCV values were categorized as low (0-10 \%), moderate (10-20\%) and high (20 and above 20) as indicated by Sivasubramanian and Menon (1973). The heritability was categorized as low (0-30 \%), moderate (30-60 \%) and high (60 and above) as given by Robinson et al., (1949). Genetic advance as per cent mean was categorized as low $(0-10 \%)$, moderate $(10-20 \%)$ and high (20 and above) as given by Johnson et al., (1955).

\section{Results and Discussion}

Genetic Variability facilitates genotypes with ability to adapt according to the conditions prevailing. The extent of genetic variability is considered as an important factor and a must pre-requisite for a successful hybridization programme. If a species lacks the opportunity to adapt itself to new condition it will ultimately get vanished. This genetic variation is the source which is exploited to improve a species and as result new efficient cultivars are achieved.

The results of ANOVA revealed that the mean sum of squares among the genotypes for all the characters were highly significant, which indicated the presence of ample genetic variability among the genotypes. Thus, it can be inferred that there is a great scope of selection of promising genotypes from the present gene pool. The General Mean, Range of variation, Genotypic (GCV) and Phenotypic (PCV) coefficients of variation, broad sense heritability $\left(\mathrm{h}_{\mathrm{b}}^{2}\right)$ and genetic advance as percent of mean (GAM) were estimated for all the morphological characters and quality parameters studied and are presented in Table 1.

\section{Variability parameters}

Days to flowering ranged from 54.00-111.00 days with a mean value of 93.3 days and had PCV and GCV of moderate level. The genotype SKG-2017-69 was earliest for days to emergence. Days to maturity ranged from 74.00-155.00 days with a mean value of 131.91 days and had moderate PCV and GCV. The genotype SKG-2017-69 showed earliest maturity. The Plant height ranged from $70.00-164.00 \mathrm{~cm}$ with mean value of $130.01 \mathrm{~cm}$. The PCV and GCV were found to be moderate. The genotype SKG-2017-61 and SKG-2017-36 were the tallest, while genotype SKG-2017-69 was dwarf. The range of number of tillers per plant varied from 4.67-11.60 with a general mean 8.17. The Phenotypic and Genotypic coefficients of variation observed to be marginally high. The genotype SKG-2017-57 produced maximum number of tillers, while genotype SKG-2017- 
30 had minimum number of tillers. The Panicle length varied from $1.87-54.53 \mathrm{~cm}$ with a mean of $43.89 \mathrm{~cm}$ The PVC and GCV was found marginally high. Longest panicle was found in the genotype SKG-2017-74, while genotype SKG-2017-69 bore the shortest panicle. Range of flag leaf length was observed from $32.33-54.33 \mathrm{~cm}$ with general mean $38.89 \mathrm{~cm}$ and had moderate PCV and GCV.

Range of flag leaf breadth was observed from $1.17-2.10 \mathrm{~cm}$ with general mean $1.52 \mathrm{~cm}$ with moderate PCV and GCV. The range of number of grains per panicle was found to be 94.33-309.33 with a mean value of 155.29. PCV and GCV were observed to be high. The genotype SKG-2017-59 produced maximum number of grains per panicle, while the genotype SKG-2017-62 had poorest number of grains per panicle.

The grain weight per panicle ranged from 1.91-6.96 $\mathrm{g}$ and the general means was found to be $3.52 \mathrm{~g}$, with high PCV and GCV. The genotype SKG-2017-59 had highest grain weight per panicle and genotype SKG-201773 had lowest grain weight per panicle. Range of grain weight per plant varied from 5.10$31.57 \mathrm{~g}$ with the mean value of $12.26 \mathrm{~g}$ and high PCV and GCV. The genotype SKG2017-56 yielded maximum grain weight per plant followed by SKG-2017-75, SKG-201759, SKG-2017-65 and SKG-2017-66.The range of 100 grain weight was $1.67-3.50 \mathrm{~g}$ with a mean value of $2.54 \mathrm{~g}$ with moderate PCV and GCV. The genotype SKG-2017-57 reflected maximum and genotype SKG-201772 showed minimum 100 grain weight.

100 kernel weight ranged from $1.20-2.67 \mathrm{~g}$ and the mean value was $1.89 \mathrm{~g}$ with moderate PCV and GCV. Highest 100 kernel weight was recorded for the genotype SKG-201757and lowest for the genotype SKG-2017-72. Hulling (\%) ranged from 65.91-85.51\% around the mean of $75.37 \%$ with low PCV and GCV. The genotype SKG-2017-67 recorded highest hulling (\%), while genotype SKG-2017-71 recorded lowest hulling (\%). Value of kernel length before cooking $(\mathrm{mm})$ ranged between $4.47-9.60 \mathrm{~mm}$ with a mean value of $7.21 \mathrm{~mm}$ and moderate PCV and GCV. The genotype SKG-2017-56 attained maximum kernel length before cooking and genotype SKG-2017-72 attained the minimum. Moderate PCV and GCV was found for kernel breadth before cooking with a general mean of $2.00 \mathrm{~mm}$ and range of 1.63 $2.80 \mathrm{~mm}$.

The maximum and minimum kernel breadth before cooking was exhibited by the genotype SKG-2017-70 and the genotype SKG-201767, respectively. Moderate PCV and GCV with wide range of $5.40-12.90 \mathrm{~mm}$ was recorded for kernel length after cooking with general mean of $9.19 \mathrm{~mm}$. The genotype SKG-2017-30 expended maximum kernel length after cooking while the genotype SKG2017-72 expended minimum. Range of kernel breadth after cooking was found between $2.10-3.90 \mathrm{~mm}$ with general mean of $2.55 \mathrm{~mm}$ and moderate PCV and GCV.

The genotype SKG-2017-47 and SKG-201766 showed maximum and minimum expansion in kernel breadth after cooking, respectively. General mean of 3.73 was found for L:B Ratio with a range of1.60-5.21 and high variability as reflected by PCV and GCV values. The genotype SKG-2017-57 and SKG-2017-70 had maximum and minimum L:B Ratio, respectively. Range of kernel elongation ratio was found between 1.06-1.54 with general mean of 1.28 and moderate PCV and GCV. The genotype SKG-2017-47 attained maximum kernel elongation ratio and genotype SKG-2017-56 attained minimum. Range of breadth increase ratio after cooking was found between 1.04-1.94 with general mean of 1.48 and moderate PCV and GCV. 
The genotype SKG-2017-55 had maximum, while the genotypes SKG-2017-74 and SKG2017-24 had minimum breadth increase ratio after cooking. Range of 100 kernel weight after cooking was found between 2.43-26.40g with General mean of $4.19 \mathrm{~g}$ and moderate PCV and GCV. The genotype SKG-2017-30 attained maximum, while the genotype SKG2017-72 attained minimum 100 kernel weight after cooking.

Range of water absorption by $10 \mathrm{~g}$ kernel was found between $5.37-24.32 \mathrm{ml}$ with general mean of $12.75 \mathrm{ml}$ and exhibited high variability as revealed by $\mathrm{PCV}$ and GCV values. The genotype SKG-2017-44 and the genotype SKG-2017-67 had showed maximum and minimum water absorption by $10 \mathrm{~g}$ kernel.

The variability among genotypes indicates ample scope for selection for different quantitative characters for rice improvement. These findings are in accordance with the findings of Singh et al., (2011), Tiwari et al., (2011) and Kumar et al., (2013), who also observed significant variability for yield and its components in rice. The magnitude of phenotypic coefficient of variation was higher than genotypic coefficient of variation for all the characters which may be due to higher degree of interaction of genotypes with the environment. Similar findings were also reported by Paul et al., (2011), Krishnamurthy and Kumar (2012) and Srivastava et al., (2017).

\section{Heritability and genetic advance}

The proportion of genetic variability which is transmitted from parents to offspring is reflected by heritability (Lush, 1949). High heritability alone is not enough to make sufficient improvement though selection in advance generation where accompanied by substantial amount of genetic advance.
Heritability along with genetic advance becomes more useful tool for the prediction of the method of improvement to be applied, rather than heritability alone. High heritability in broad sense coupled with high genetic advance as percent of mean was estimated for days to flowering, days to maturity, plant height, number of tillers per plant, panicle length, flag leaf length, flag leaf breadth, number of grains per panicle, grains weight per panicle, grain weight per plant, 100 grain weight, 100 kernel weight, kernel length before cooking, kernel breadth before cooking, kernel length after cooking, kernel breadth after cooking, L:B Ratio, kernel elongation ratio, breadth increase ratio after cooking,100kernel weight after cooking and water absorption by $10 \mathrm{~g}$ kernel. High broad sense heritability along with moderate genetic advance as percent of mean was found for hulling $\%$.

Johnson et al., (1995) suggested that heritability and genetic advance when calculated together would prove more useful in predicting the resultant effect of selection on phenotypic expression. The results revealed that high heritability coupled with high genetic advance as percentage of mean was registered for all the characters except hulling percent, suggesting preponderance of additive gene action in the expression of these characters. Therefore, selection may be effective through these characters.

High heritability associated with moderate genetic advance as percent of mean was observed for hilling \%, which revealed the non-additive gene action in the expression of this characters in their inheritance, hence in this case selection may not be effective. These findings were in agreement with the findings of earlier researcher Akinwale et al., (2011), Kumar et al., (2011), Kumar and Verma (2015), Sravan et al., (2016), Devi et al., 2017 and Tripathi et al., (2018). 
Table.1 Mean, Range, Phenotypic (PCV) and Genotypic (GCV) Coefficients of Variation, Heritability $\left(\mathrm{h}^{2}\right)$, Genetic advance (GA) and Genetic advance as percent of mean (GAM) for yield components and quality parameters in basmati rice

\begin{tabular}{|c|c|c|c|c|c|c|c|}
\hline Character & Mean & Range & PCV & GCV & $\mathbf{h}^{2}$ & GA & $\begin{array}{c}\text { GA as \% of } \\
\text { Mean }\end{array}$ \\
\hline Days to $50 \%$ flowering & 93.30 & $54.00-111.00$ & 13.42 & 13.13 & 95.73 & 24.69 & 26.46 \\
\hline Plant height (cm) & 130.01 & $70.00-164.00$ & 18.15 & 18.04 & 98.73 & 47.99 & 36.91 \\
\hline Number of tillers per plant & 8.17 & $4.67-11.60$ & 21.07 & 20.87 & 98.15 & 3.48 & 42.59 \\
\hline Flag leaf length $(\mathrm{cm})$ & 38.89 & $32.33-54.33$ & 15.15 & 14.35 & 89.74 & 10.89 & 28.00 \\
\hline Flag leaf with $(\mathrm{cm})$ & 1.52 & $1.17-2.10$ & 13.93 & 11.97 & 73.90 & 0.32 & 21.05 \\
\hline Number of grains per panicle & 155.29 & $94.33-309.33$ & 36.31 & 36.22 & 99.53 & 115.58 & 74.43 \\
\hline Grain weight per panicle (g) & 3.52 & $1.91-6.96$ & 35.17 & 35.06 & 99.41 & 2.53 & 71.88 \\
\hline Grain weight per plant (g) & 12.26 & $5.10-31.57$ & 43.34 & 43.15 & 99.16 & 10.85 & 88.50 \\
\hline 100 grain weight $(\mathrm{g})$ & 2.54 & $1.67-3.50$ & 16.91 & 16.37 & 93.69 & 0.83 & 32.68 \\
\hline $\begin{array}{l}\text { Kernel breadth before cooking } \\
(\mathrm{mm})\end{array}$ & 2.00 & $1.63-2.80$ & 14.24 & 12.55 & 77.63 & 0.46 & 23.00 \\
\hline Kernel length after cooking (mm) & 9.19 & $5.40-12.90$ & 20.35 & 20.32 & 99.73 & 3.84 & 41.78 \\
\hline Kernel breadth after cooking (mm) & 2.55 & $2.10-3.90$ & 16.92 & 16.60 & 96.32 & 0.86 & 33.73 \\
\hline L:B ratio & 3.73 & $1.60-5.21$ & 26.61 & 25.92 & 94.95 & 1.94 & 52.01 \\
\hline Kernel elongation ratio & 1.28 & $1.06-1.54$ & 10.70 & 10.57 & 97.70 & 0.27 & 21.09 \\
\hline Breadth increase ratio after cooking & 1.48 & $1.04-1.94$ & 16.93 & 13.75 & 66.00 & 0.30 & 20.27 \\
\hline 100 kernel weight after cooking (g) & 4.19 & $2.43-6.40$ & 19.91 & 19.66 & 97.46 & 1.67 & 39.86 \\
\hline Water absorb by $10 \mathrm{~g}$ kernel (ml) & 12.75 & $5.37-24.32$ & 39.30 & 36.78 & 87.58 & 9.04 & 70.90 \\
\hline
\end{tabular}


It is therefore concluded that the morphological characters such as days to flowering, days to maturity, plant height, number of tillers per plant, panicle length, flag leaf length, flag leaf breadth, number of grains per panicle, grains weight per panicle, grain weight per plant, 100 grain weight and quality parameters viz., 100 kernel weight, kernel length before cooking, kernel breadth before cooking, kernel length after cooking, kernel breadth after cooking, L:B Ratio, kernel elongation ratio, breadth increase ratio after cooking, 100 kernel weight after cooking and water absorption by $10 \mathrm{~g}$ kernel could be utilized as selection indices for direct selection to improve the basmati rice genotypes for yield as well as quality.

On the basis of study, the desirable donors for each character were identified. The most promising donors for grain yield were SKG2017-56, SKG-2017-75, SKG-2017-65, SKG2017-59, SKG-2017-66, These genotypes can be used for further breeding programme to improve the yield potential of the varieties.

\section{References}

Akinwale, M.C., Gregoria, G., Nwilene, F., Akinyele, B.O., Ogunbayo S.A. and Odiyi A.C. (2011). Heritability and correlation coefficient analysis for yield and its components in rice (Oryza sativa L.) African journal of Plant Science. 5(3):207-212.

Burton, G. W. (1952). Quantitative inheritance in grasses. Proc. 6th Interaction. Grassland Cong. J. 1: 227283.

Burton G.W. and De Vane E.H. (1953). Estimating heritability in tall fescue (Festuca arundinacea) from replicated clonal material. Agronomy J. 45: 478481.

Devi, K. R., Chandra, B. S., Lingaiah N., Hari Y. and Venkanna V. (2017).
Analysis of variability, correlation and path coefficient studies for yield and quality traits in rice (Oryza sativa L.) Agricultural Science Digest. 37(1):1-9

Falconer D.S. (1985). Introduction to Quantitative Genetics. ELBS, Longman.

Johnson, H. W., Robinson, H. F. and Comstock, R. E. (1955). Estimates of genetic and environmental variability in soybeans. Agronomy Journal, 47(7): 314-318

Krishnamurthy H.T., and Kumar H.D.M. (2012). Correlation and path coefficient studies of some physiological traits among indigenous aromatic rice (Oryza sativa L) cultivars. Agricultural \& Biological Research. 28(2):120- 127

Kumar, A, Rangare, N. R. And Vidyakar, V. (2013). Study of genetic variability of Indian and exotic rice germplasm in Allahabad agroclimate. The Bioscan 8(4): 1445-1451

Kumar, A. and Verma, O.P. (2015). Correlation and path coefficient analysis in certain quantitative traits in rice (Oryza sativa L.) under saline-alkaline condition. Res. Envi. Life Sci. 8(3):443446

Kumar, Y., Singh, B.N., Verma, O.P., Tripathi, S. and Dwivedi, D.K. 2011. Correlation and path coefficient analysis in scented rice (Oryza sativa L.) under sodicity, Environment and Ecology. 29(3B):1550-1556.

Lush J.L. (1949). Heritability of quantitative characters in farm animals. Hereditas, suppl,356-375.

Panse V.G. and Sukhatme P.V. (1967). Statistical methods of agricultural workers. $2^{\text {nd }}$ edition, pp:381, I.C.A.R. Publ. New Delhi.

Paul, A., Babu, G. S., Lavanya, G. R. and Singh, C. M. (2011). Variation and association among yield and yield components in upland rice (Oryza 
sativa L.). Environment and Ecology, 29(2): 690-695.

Robinson, H. F., Comstock, R. E. and Harvey, P. H. 1949. Estimates of heritability and degree of dominance in corn. Agron. J. 41:353-359.

Singh, S., C. Singh, and G. M. Lal. (2011). Assessment of Genetic Variability for Yield and Its Component Characters in Rice (Oryza sativa L.)". Research in Plant Biology, 1(4): 73-76.

Sivasubramanian, S. and Madhava Menon, P. (1973). Genotypic and phenotypic variability in rice, Madras Agric. J., 60: 1093-1096.

Sravan, T., Jaiswal, H.K., Waza, S.

A., Kumari, P. (2016). Analysis of Variability and Character Association in Indigenous Aromatic Rice (Oryza sativa L.) Electronic Journal of Plant
Breeding. 7(1):159-164

Srivastava, N., Babu, G. S., Singh, O. N., Verma, R. L. and Pathak, S. K. (2017). Appraisal of genetic variability and character association studies in some exotic upland rice germplasm. Plant Archives. 17(2):1581-1586

Tiwari D.K., Pandey, P., Tripathi, S., Giri, S.P. and Dwivedi, J.L. (2011). Studies on genetic variability for yield components in rice (Oryza sativa L.). Advances in Agriculture \& Botanics. 3(1):76-81

Tripathi, N., Verma, O.P., Singh, P.K. and Rajpoot, P. (2018). Studies on correlation and path coefficient analysis for yield and its components in rice (Oryza sativa L.) under salt affected soil. Journal of Pharmacognosy and Phytochemistry. 7(3): 1626-1629.

\section{How to cite this article:}

Amod Kumar, Shiv Kumar, Sarvendra Singh, Janeshwar Prasad, A. S. Jeena and Upreti. M. C. 2020. Studies on Genetic Parameters for Quality Traits and Yield Components in Basmati Rice (Oryza sativa L.). Int.J.Curr.Microbiol.App.Sci. 9(06): 1525-1532. doi: https://doi.org/10.20546/ijcmas.2020.906.188 